Check for updates

Cite this: Chem. Sci., 2017, 8, 6375

Received 17th April 2017

Accepted 8th July 2017

DOI: $10.1039 / \mathrm{c} 7 \mathrm{sc} 01703 \mathrm{k}$

rsc.li/chemical-science

\section{Metal-free di- and tri-fluoromethylation of alkenes realized by visible-light-induced perylene photoredox catalysis $\uparrow$}

\author{
Naoki Noto, Takashi Koike (D) * and Munetaka Akita (D) * \\ Regioselective amino-difluoromethylation of aromatic alkenes via $\mathrm{C}\left(\mathrm{sp}^{3}\right)-\mathrm{CF}_{2} \mathrm{H}$ and $\mathrm{C}\left(\mathrm{sp}^{3}\right)-\mathrm{N}$ bond \\ formation with the $\mathrm{C}=\mathrm{C}$ moiety has been achieved in a single operation by visible-light photoredox \\ catalysis. The combination of a shelf-stable and easy-to-handle sulfonium salt, $S$-difluoromethyl-S-di( $p$ - \\ xylyl)sulfonium tetrafluoroborate, and perylene catalysis is the key to the successful transformation. \\ Furthermore, this noble metal-free protocol allows for the photocatalytic trifluoromethylation of alkenes.
}

\section{Introduction}

The trifluoromethyl $\left(\mathrm{CF}_{3}\right)$ and difluoromethyl $\left(\mathrm{CF}_{2} \mathrm{H}\right)$ groups have prevailed as key structural motifs of drugs and agrochemicals. ${ }^{1}$ In particular, the $\mathrm{CF}_{2} \mathrm{H}$ group is regarded as a unique fluorinated group because it acts as a bioisostere to hydroxyl and thiol units as well as a lipophilic hydrogen donor. Recently, practical trifluoromethylation has been realized by the action of appropriate catalysis to a variety of $\mathrm{CF}_{3}$ sources. ${ }^{2}$ In contrast, versatile strategies for the direct difluoromethylation of various carbon skeletons are still underdeveloped. ${ }^{3}$

In the past several years, visible-light photoredox catalysis with metal catalysts such as $\left[\mathrm{Ru}(\mathrm{bpy})_{3}\right]^{2+}$ and $\mathrm{fac}$ - $\left[\operatorname{Ir}(\mathrm{ppy})_{3}\right]$ (bpy $=2,2^{\prime}$-bipyridine, ppy $=2$-phenylpyridyl) has emerged as a useful tool for radical trifluoromethylation. ${ }^{4}$ In particular, shelf-stable and solid sulfonium salts such as Umemoto $\mathbf{A}^{5}$ and Yagupolskii $\mathbf{B}^{6}$ reagents readily undergo single-electron transfer (SET) from photoactivated catalysts to serve as excellent $\mathrm{CF}_{3}$ radical precursors (Fig. 1). ${ }^{7,8}$ More recently several groups, including us, have developed novel strategies for generation of the $\mathrm{CF}_{2} \mathrm{H}$ radical from well-designed $\mathrm{CF}_{2} \mathrm{H}$ sources such as sulfonyl derivatives (C-E) and phosphonium salts F. ${ }^{9}$ Remarkably, the subtle change in the number of fluorine atoms in the $\mathrm{CF}_{2} \mathrm{X}$ reagents $(\mathrm{X}=\mathrm{F}, \mathrm{H})$ causes significant differences in their chemical properties such as redox performance and stability. For example, generation of the $\mathrm{CF}_{2} \mathrm{H}$ radical from electrophilic $\mathrm{CF}_{2} \mathrm{H}$ sources as presented herein demands a stronger reductant compared with the $\mathrm{CF}_{3}$ radical. In general, the Ir

Laboratory for Chemistry and Life Science, Institute of Innovative Research, Tokyo Institute of Technology, R1-27, 4259 Nagatsuta-cho, Midori-ku, Yokohama, 226-8503, Japan.E-mail: koike.t.ad@m.titech.ac.jp; makita@res.titech.ac.jp

$\dagger$ Electronic supplementary information (ESI) available: Experimental details, spectral data, and crystallographic results. CCDC 1533276 and 1533274. For ESI and crystallographic data in CIF or other electronic format see DOI: 10.1039/c7sc01703k photocatalyst, $f a c$ - $\left[\operatorname{Ir}(\mathrm{ppy})_{3}\right]$, is regarded as a strong 1e-reductant when excited by visible light irradiation. But from the viewpoint of the elements strategy initiative ${ }^{10}$ and green chemistry, development of organic photocatalytic systems has attracted great interest. ${ }^{11}$ However, the design of visible-light organic photoredox catalysts with stronger reduction power still leaves room for further development. In 2014, König and co-workers developed the consecutive photoinduced electron transfer (conPET) of perylene diimide, but it requires sacrificial electron donors. ${ }^{12}$ The groups of Hawker and Miyake reported that phenylphenothiazine and diaryl dihydrophenazine serve as strong reductants, respectively. ${ }^{13}$ Then, simple polycyclic aromatic hydrocarbons (PAHs) attracted our attention. It is known that some PAHs exhibit high excited state energies
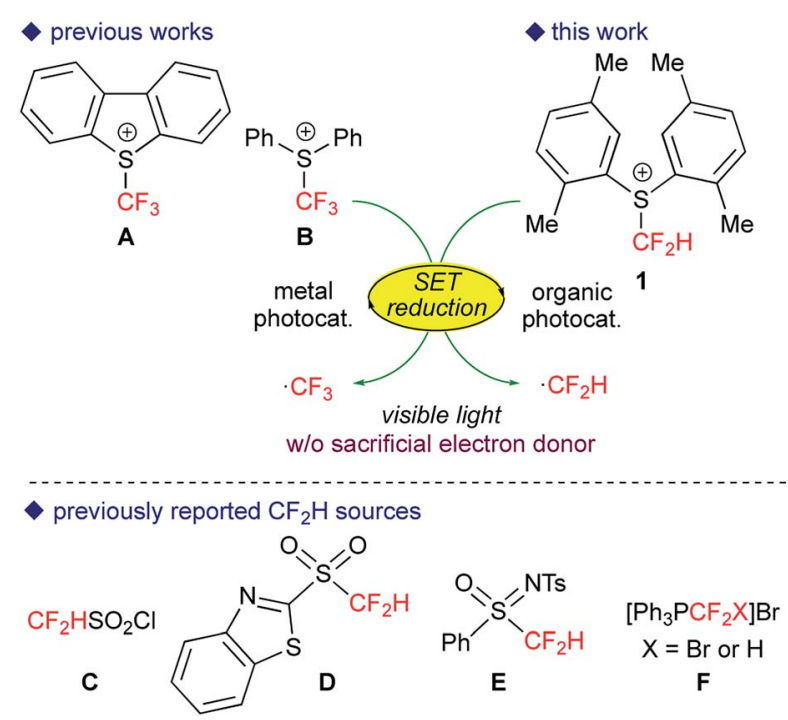

Fig. 1 Reductive generation of fluoroalkyl radicals by SET photoredox catalysis. Ts $=p$-toluenesulfonyl. 
accompanied by relatively high HOMO levels, ${ }^{\mathbf{1 4}}$ suggesting that they can serve as efficient and economical photoredox catalysts without extra reductants. Herein, we disclose that perylene can serve as an excellent visible-light organic photocatalyst for amino-difluoromethylation of aromatic alkenes in a single operation. The present noble metal-free photocatalytic system also allows trifluoromethylation of alkenes.

\section{Results and discussion}

We first tackled the synthesis of a shelf-stable and easy-tohandle electrophilic $\mathrm{CF}_{2} \mathrm{H}$ source. In 2007, Prakash, Olah and co-workers reported on the synthesis of the $S$-difluoromethyl- $S$ phenyl-S-2,3,4,5-tetramethylphenylsulfonium reagent $\mathbf{G},{ }^{\mathbf{1 5}}$ which reacted with various hetero-atom-nucleophiles resulting in the formation of $\mathrm{X}-\mathrm{CF}_{2} \mathrm{H}$ bonds $(\mathrm{X}=\mathrm{N}, \mathrm{O}, \mathrm{P})$, but construction of a $\mathrm{C}\left(\mathrm{sp}^{3}\right)-\mathrm{CF}_{2} \mathrm{H}$ bond has not been reported. In addition, the reagent $\mathbf{G}$ is semi-solid and not very stable, and so decomposes by $\sim 10 \%$ after three months even when stored at $-20{ }^{\circ} \mathrm{C}$. Therefore, we designed the $S$-(difluoromethyl)sulfonium reagent $(\mathbf{1})$, where the two methyl groups of the $p$-xylyl substituents in the proximity of the sulfur atom may hinder decomposition via ionic and carbenoid reactions due to steric and electronic effects. The reagent 1 was easily synthesized according to the procedures modified from the original ones ${ }^{15,16}$ and characterized by ${ }^{1} \mathrm{H},{ }^{13} \mathrm{C}$ and ${ }^{19} \mathrm{~F}$ NMR spectroscopy and elemental analysis. The structure of 1 was confirmed by single crystal X-ray analysis (Scheme 1). ${ }^{17}$ Compound $\mathbf{1}$ is a stable, crystalline white solid. It is worth noting that no decomposition was observed of a solid sample on a shelf for three months at ambient temperature, while a $\mathrm{CH}_{3} \mathrm{CN}$ solution partially decomposed ( $\sim 10 \%$ ) when left for $24 \mathrm{~h}$ at ambient temperature. In addition, a cyclic voltammogram of $\mathbf{1}$ exhibited a broad irreversible reduction wave at around $-1.70 \mathrm{~V} v s$. $\left[\mathrm{Cp}_{2} \mathrm{Fe}\right]$.

With this new reagent in hand, we explored the photoredoxcatalyzed amino-difluoromethylation of styrene $2 \mathbf{a}$, which would lead to potentially useful $\beta-\mathrm{CF}_{2} \mathrm{H}$ substituted amines. ${ }^{18}$ To design an organic photocatalytic system under visible light irradiation, absorption bands in the visible light region are vital. Pale-colored PAHs with large $\pi$-conjugated systems may work as visible-light catalysts. We commenced the reaction of $\mathbf{2 a}$
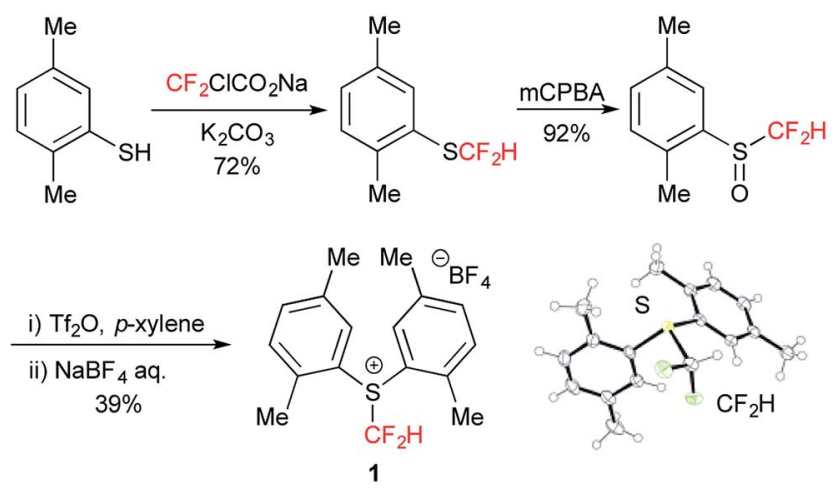

Scheme 1 Synthesis and an ORTEP drawing ( $\mathrm{BF}_{4}$ anion: omitted) of 1 . in the presence of $10 \mathrm{~mol} \%$ perylene (absorption maxima: 434, $407 \mathrm{~nm}$ ) in $\mathrm{CD}_{3} \mathrm{CN}$ containing an equimolar amount of $\mathrm{D}_{2} \mathrm{O}$, under visible light irradiation with $425 \mathrm{~nm}$ blue LEDs. To our delight, deuterated $N$-(3,3-difluoro-1-phenylpropyl)acetamide $3 \mathbf{a}-d_{4}$ was obtained in a $96 \%$ yield (entry 1 in Table 1 ). In contrast, analogous PAHs such as anthracene and pyrene were totally ineffective, presumably because of a lack of a visible absorption band, while 9,10-dimethylanthracene worked to some extent (entries 2-4). It is worth noting that the Ir photocatalyst, $f a c-\left[\operatorname{Ir}(\mathrm{ppy})_{3}\right]$, was sluggish (entry 5). The estimated reduction potential of the photoexcited perylene was remarkably high $\left(-2.23 \mathrm{~V} v s\right.$. $\left[\mathrm{Cp}_{2} \mathrm{Fe}\right]$ in $\mathrm{CH}_{3} \mathrm{CN}$, see the ESI $\left.\dagger\right)$ and even higher than that of $f a c$ - $\left[\operatorname{Ir}(\mathrm{ppy})_{3}\right](-2.14 \mathrm{~V}$ (ref. 19)), which has been regarded as the most strongly reducing visible-light photoredox catalyst. The quantum yield of the emission of *perylene $\left(94 \%\right.$ (ref. 14)) is far superior to that of *[fac-[Ir(ppy) $\left.{ }_{3}\right]$ (38\% (ref. 19)), but the emissive excited state of perylene has a very short lifetime (8.2 ns). Thus, perylene has been studied extensively as a fluorescent molecule, but less attention has been paid to it as a photoredox catalyst. ${ }^{20}$ Using 1.1 equivalents of 1 decreased the yield (entry 6). The reaction did not proceed at all either in the dark or in the absence of perylene (entries 7 and 8).

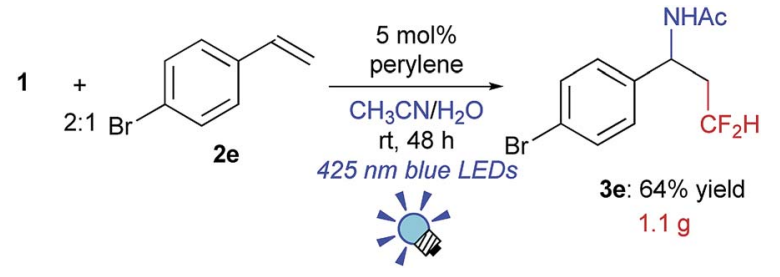

Furthermore, the reactions of neutral halogen-free sulfonyl derivatives ( $\mathbf{D}$ and $\mathbf{E}$ ) and sulfonium reagent $\mathbf{G}$ were conducted under optimized conditions (entries 9-11). It should be noted that the sulfonium reagents ( $\mathbf{1}$ and $\mathbf{G}$ ) are superior to $\mathbf{D}$ and $\mathbf{E}$ in this photocatalytic reaction. The sulfonium reagent $\mathbf{G}$ also served as an effective $\mathrm{CF}_{2} \mathrm{H}$ source (entry 11 ), but the stability and handling of reagent $\mathbf{1}$ were significantly improved.

We further investigated the scope of this reaction (Table 2) and found that the catalyst loading could be reduced to $5 \mathrm{~mol} \%$. The reaction of styrene derivatives with a variety of functional groups such as $\mathrm{Me}(\mathbf{2 b}), \mathrm{F}(\mathbf{2 c}),{ }^{17} \mathrm{Cl}(\mathbf{2 d}), \mathrm{Br}$ (2e), AcO (2f), Bpin $(\mathbf{2 g})$ and aldehyde (2h) groups afforded the corresponding $\beta$ $\mathrm{CF}_{2} \mathrm{H}$ substituted amino compounds (3b-g) in $30-76 \%$ yields in a regioselective manner. To demonstrate the scalability of this organic photocatalytic system, the amino-difluoromethylation of 2e was carried out on a gram scale, and the product $3 \mathbf{e}$ was isolated in a $64 \%$ yield (1.1 g) (eqn (1)). It is worth noting that this reaction could be applied to a structurally more complex estrone derivative (2i) (3i: 38\%). An alkene with a bulky mesityl substituent (2j) was also a substrate suitable for this transformation (3j: $52 \%$ ), but 1,1-diphenylethylene (2k) afforded the substituted $\mathrm{CF}_{2} \mathrm{H}$-alkene (4) in a $55 \%$ yield via deprotonation from the carbocationic intermediate (vide infra). Furthermore, the system was amenable to the regioselective reaction of the internal alkenes. The reactions of trans- $\beta$-methylstyrene (2l), 
Table 1 Optimization of the photocatalytic amino-difluoromethylation of $2 a^{a}$

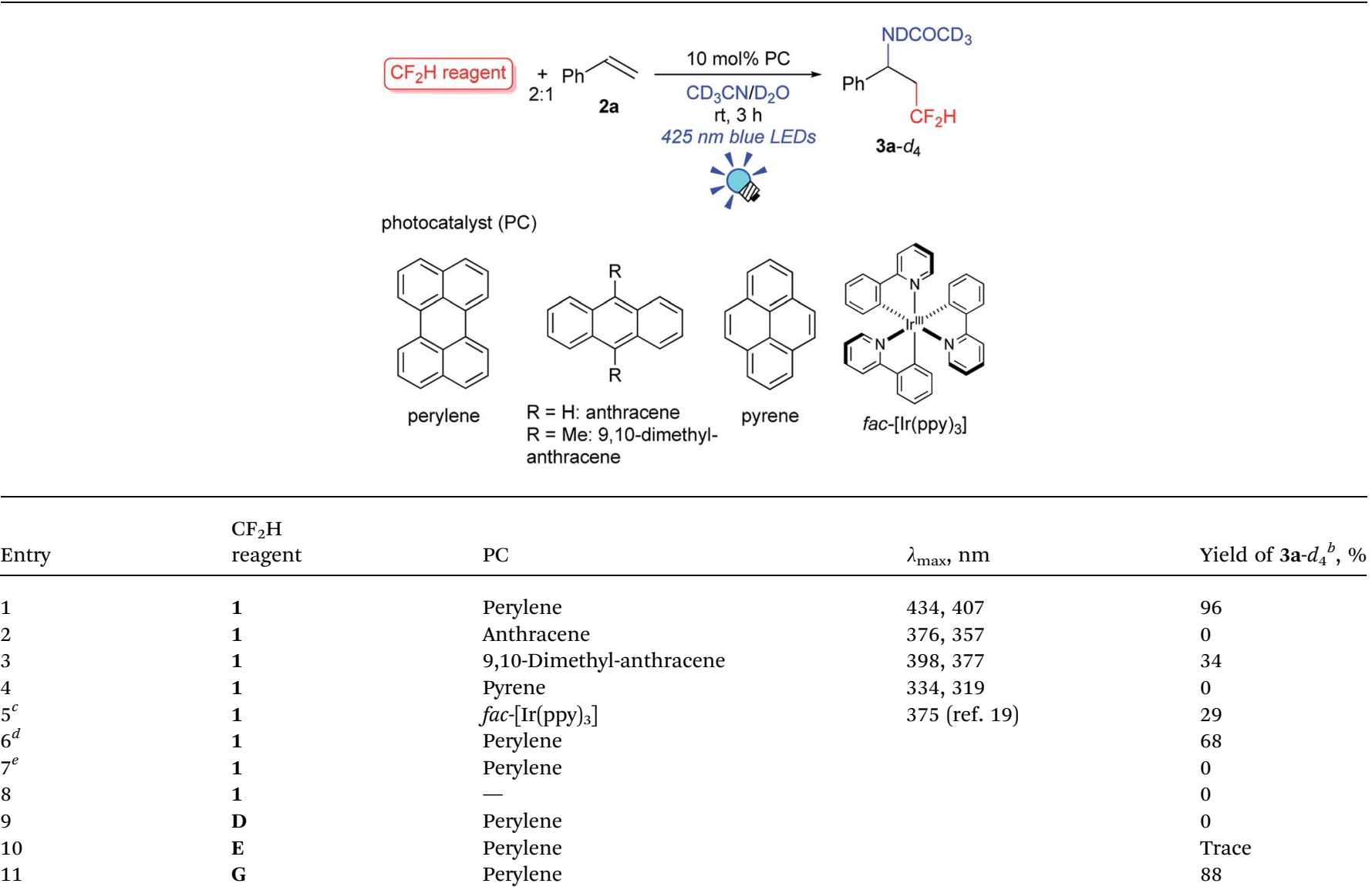

${ }^{a}$ The reaction was carried out under $\mathrm{N}_{2}$ atmosphere and irradiation of $425 \mathrm{~nm}$ blue LEDs at room temperature using the photocatalyst (2.5 $\mu$ mol), $\mathrm{CF}_{2} \mathrm{H}$ reagent $(50 \mu \mathrm{mol}), 2 \mathrm{a}(25 \mu \mathrm{mol})$, and $\mathrm{CD}_{3} \mathrm{CN}\left(0.50 \mathrm{~mL}\right.$ : containing $25 \mu \mathrm{mol}$ of $\left.\mathrm{D}_{2} \mathrm{O}\right)$ in an NMR tube. ${ }^{b}$ Yields were determined by ${ }^{1} \mathrm{H}$ NMR spectroscopy using $\mathrm{SiEt}_{4}$ as an internal standard. ${ }^{c} \mathrm{~A} 71 \%$ NMR yield of $3 \mathrm{a}-d_{4}$ was obtained in 24 h. ${ }^{d}$ The ratio of $1: 2 \mathrm{a}$ is $1.1: 1 .{ }^{e}$ In the dark. LED $=$ light-emitting diode, $\mathrm{ppy}=2$-phenylpyridyl .

trans-stilbene (2m), and 1,2-dihydronaphthalene (2n) provided the $\mathrm{CF}_{2} \mathrm{H}$-substituted amino products (31-n) in $44-64 \%$ yields but as mixtures of diastereomers. Remarkably, cinnamic acid ester (2o) could also be used for this transformation, resulting in the production of a $\mathrm{CF}_{2} \mathrm{H}$-substituted $\beta$-amino acid derivative (3o: $60 \%$ ). These results showed that this metal-free photocatalytic system with the $\mathrm{CF}_{2} \mathrm{H}$ reagent $\mathbf{1}$ is useful for regioselective and simultaneous construction of $\mathrm{C}\left(\mathrm{sp}^{3}\right)-\mathrm{CF}_{2} \mathrm{H}$ and $\mathrm{C}\left(\mathrm{sp}^{3}\right)-\mathrm{N}$ bonds onto a $\mathrm{C}=\mathrm{C}$ moiety regardless of the functionalities.

Next, to examine the scope with respect to fluoroalkylation, the perylene-catalyzed system was applied to trifluoromethylation (Scheme 2). The reaction of styrene 2a with the reagent $\mathbf{B}$ afforded the amino-trifluoromethylated product $\mathbf{5}$ in a $66 \%$ yield. $^{7 b}$ Perylene also promoted chlorotrifluoromethylation of the aliphatic alkene $2 \mathbf{p}$ with $\mathrm{CF}_{3} \mathrm{SO}_{2} \mathrm{Cl}$ to give the product 6 in a $57 \%$ yield. ${ }^{21}$

To gain insight into the reaction mechanism we conducted some experiments. The reaction of 1-phenyl-2-(1phenylethenyl)cyclopropane (2q) afforded the difluoromethylated, ring-opened product 7 (23\% yield), indicating the involvement of radical processes in the photocatalytic reaction
(Scheme 3). Moreover, the reaction of $2 \mathrm{a}$ with 1 required continuous visible light irradiation for steady conversion (see the ESI $\dagger$ ), suggesting that a radical chain mechanism was not the main reaction pathway.

On the basis of the above-mentioned observations, a possible reaction mechanism for perylene-catalyzed difluoromethylation is depicted in Scheme 4. Perylene excited by visible light irradiation (*perylene) undergoes SET to the electrophilic $\mathrm{CF}_{2} \mathrm{H}$ reagent 1 to form the difluoromethyl radical ${ }^{\circ} \mathrm{CF}_{2} \mathrm{H}$ via $\mathrm{C}-\mathrm{S}$ bond cleavage, and the radical cation of perylene ([perylene $]^{++}$). The very short lifetime of *perylene may be compensated by its highly emissive quantum yield to promote the SET process. Fluorescence quenching experiments support the SET process (see the ESI $\dagger$ ). The generated ${ }^{\circ} \mathrm{CF}_{2} \mathrm{H}$ radical reacts with alkene 2 to form the adduct 8 , which is oxidized by [perylene] $]^{++}$to provide the carbocationic intermediate $\mathbf{8}^{+}$. Subsequent Ritter amination ${ }^{22}$ of $8^{+}$with $\mathrm{CH}_{3} \mathrm{CN} / \mathrm{H}_{2} \mathrm{O}$ affords the aminodifluoromethylated product 3 . When an $\alpha$-substituted styrene $2 \mathbf{k}$ is used as a substrate, deprotonation of $\mathbf{8}^{+}$gives the $\mathrm{CF}_{2} \mathrm{H}$-alkene 4 . 
Table 2 Scope of the perylene-catalyzed amino-difluoromethylation of alkenes ${ }^{a b}$

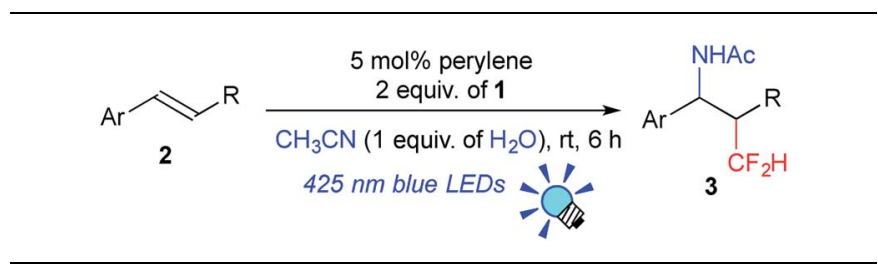<smiles>NC(=O)C(Cc1ccccc1)c1ccccc1</smiles><smiles>Cc1ccc(C(CC(F)(F)F)NCCC(F)(F)F)cc1</smiles>

3b: $43 \%$<smiles>CCCCCCCC(N)c1ccc(Cl)cc1</smiles><smiles>NC(C[TeH])C(=O)O</smiles>

3d: $61 \%$<smiles>NC(CC(F)(F)F)c1ccc(Cc2ccccc2)cc1</smiles>

3e: $71 \%$<smiles>CNC(CC(F)(F)F)c1cccc(C=O)c1</smiles><smiles>[CH]CC(NC)c1ccc2c(c1)CC[C@@H]1[C@@H]2CC[C@]2(C)C(=O)CC[C@@H]12</smiles>

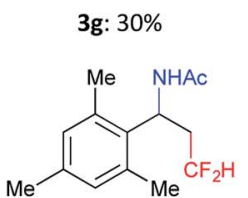

$3 h^{c}: 41 \%$<smiles>[CH-]C=C(c1ccccc1)c1ccccc1</smiles>

$3 \mathrm{j}: 52 \%$<smiles>CC(=O)C(c1ccccc1)C(c1ccccc1)C(F)(F)F</smiles>

3m: $64 \%, 83: 17 \mathrm{dr}$ 3i: $38 \%$<smiles>O=C(NC(CCP)c1ccc(F)cc1)c1ccccc1</smiles>

$3 c^{c}: 59 \%$<smiles>CC(=O)Oc1ccc(C(C[TeH])C(N)=O)cc1</smiles>

3f: $60 \%$<smiles>CC(C)C(NC(=O)[O-])C([Ge])c1ccccc1</smiles>

31: $45 \%, 71: 29 \mathrm{dr}$<smiles>CCNC(C(OC(C)=O)C(=O)F)C(C)c1ccccc1</smiles>

$30^{c}: 60 \%, 73: 27 \mathrm{dr}$
${ }^{a}$ For detailed reaction conditions, see the ESI. $\dagger^{b}$ Yields of the isolated products are lower than those before purification. The purification processes decreased the isolated yields. The diastereomer ratios (dr) were determined using ${ }^{1} \mathrm{H}$ NMR spectra of crude reaction mixtures. ${ }^{c} 12 \mathrm{~h}$. Ac $=$ acetyl, Bpin $=$ boronic acid pinacol ester.

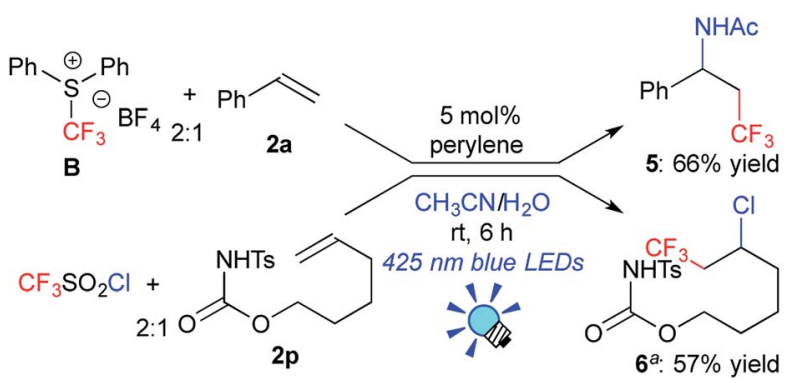

Scheme 2 Perylene-catalyzed trifluoromethylation. anhydrous $\mathrm{CH}_{3} \mathrm{CN}$ was used as a solvent.

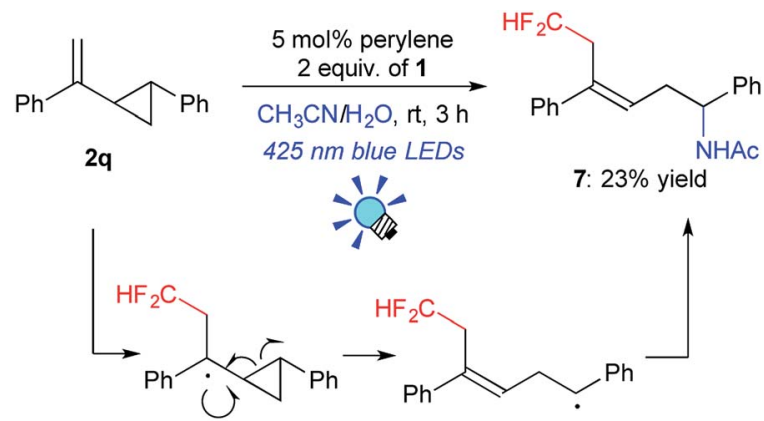

Scheme 3 Control experiment for radical difluoromethylation.

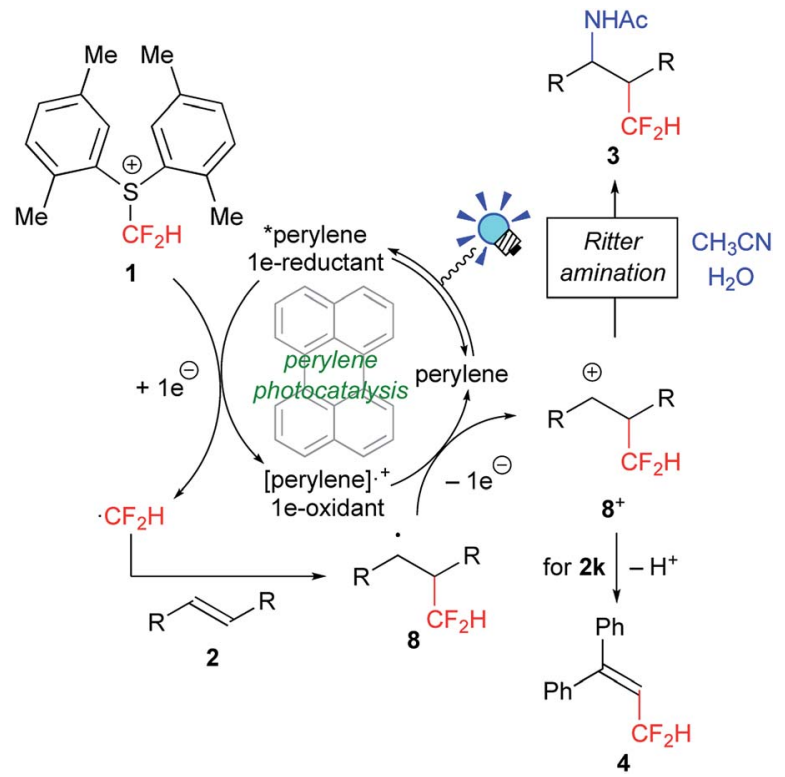

Scheme 4 A plausible reaction mechanism.

\section{Conclusions}

In conclusion, we have developed noble metal-free photocatalytic di- and tri-fluoromethylation of alkenes using a perylene catalyst. The combination of the new $S$-(difluoromethyl) sulfonium salt (1) and perylene catalysis allows for facile aminodifluoromethylation of aromatic alkenes through radical processes, for which the Ir photocatalyst works much less efficiently. Thus, the unprecedented simple synthesis of $\beta-\mathrm{CF}_{2} \mathrm{H}$ substituted amines from alkenes has now become feasible. Further development of perylene-catalyzed reactions is currently under way in our laboratory.

\section{Acknowledgements}

The authors thank the JSPS (KAKENHI Grants 22350026, 17J07953, JP16H06038, and JP16H01009 in Precisely Designed Catalysts with Customized Scaffolding), the Naito Foundation, and Asahi Glass Co., LTD. This work was performed under the Cooperative Research Program of the "Network Joint Research Center for Materials and Devices". 


\section{Notes and references}

1 (a) Fluorine in Medicinal Chemistry and Chemical Biology, ed. I. Ojima, Wiley-Blackwell, Chichester, 2009; (b) N. A. J. Meanwell, Med. Chem., 2011, 54, 2529; (c) Modern Fluoroorganic Chemistry, ed. P. Kirsch, Wiley-VCH, Weinheim, 2013.

2 For recent selected reviews on catalytic trifluoromethylation, see: (a) A. Studer, Angew. Chem., Int. Ed., 2012, 51, 8950; (b) H. Egami and M. Sodeoka, Angew. Chem., Int. Ed., 2014, 53, 8294; (c) J. Charpentier, N. Früh and A. Togni, Chem. Rev., 2015, 115, 650; (d) C. Alonso, E. M. de Marigorta, G. Rubiales and F. Palacios, Chem. Rev., 2015, 115, 1847.

3 (a) J. Hu, W. Zhang and F. Wang, Chem. Commun., 2009, 7465; (b) M.-C. Belhomme, T. Besset, T. Poisson and X. Pannecoucke, Chem.-Eur. J., 2015, 21, 12836; (c) J. Rong, C. Ni and J. Hu, Asian J. Org. Chem., 2017, 6, 139.

4 (a) T. Koike and M. Akita, Top. Catal., 2014, 57, 967; (b) S. Barata-Vallejo, S. M. Bonsei and A. Postigo, Org. Biomol. Chem., 2015, 13, 11153; (c) X. Pan, H. Xia and J. Wu, Org. Chem. Front., 2016, 3, 1163; (d) T. Chatterjee, N. Iqbal, Y. You and E. J. Cho, Acc. Chem. Res., 2016, 49, 2284; (e) T. Koike and M. Akita, Acc. Chem. Res., 2016, 49, 1937.

5 T. Umemoto and S. Ishihara, J. Am. Chem. Soc., 1993, 115, 2156-2164.

6 (a) V. V. Lyalin, V. V. Orda, L. A. Alekseeva and L. M. Yagupolskii, Zh. Org. Khim., 1984, 20, 115; (b) J.-J. Yang, R. L. Kirchmeier and J. M. Shreeve, J. Org. Chem., 1998, 63, 2656.

7 (a) Y. Yasu, T. Koike and M. Akita, Angew. Chem., Int. Ed., 2012, 51, 9567; (b) Y. Yasu, T. Koike and M. Akita, Org. Lett., 2013, 15, 2136; (c) N. Noto, K. Miyazawa, T. Koike and M. Akita, Org. Lett., 2015, 17, 3710; (d) R. Tomita, T. Koike and M. Akita, Angew. Chem., Int. Ed., 2015, 54, 12923.

8 M. Li, Y. Wang, X.-S. Xue and J.-P. Cheng, Asian J. Org. Chem., 2017, 6, 235.

9 For selected examples of photocatalytic incorporation of the $\mathrm{CF}_{2} \mathrm{H}$ group, see: (a) X.-J. Tang and W. R. Dolbier Jr, Angew. Chem., Int. Ed., 2015, 54, 4246; (b) Z. Zhang, X. Tang, C. S. Thomoson and W. R. Dolbier Jr, Org. Lett., 2015, 17, 3528; (c) W. Fu, X. Han, M. Zhu, C. Xu, Z. Wang, B. Ji, X.-Q. Hao and M.-P. Song, Chem. Commun., 2016, 52, 13413; (d) Q.-Y. Lin, X.-H. Xu, K. Zhang and F.-L. Qing, Angew. Chem., Int. Ed., 2016, 55, 1479; (e) J. Rong, L. Deng, P. Tan, C. Ni, Y. Gu and J. Hu, Angew. Chem., Int. Ed., 2016, 55, 2743; (f) Y. Arai, R. Tomita, G. Ando, T. Koike and
M. Akita, Chem.-Eur. J., 2016, 22, 1262; (g) Q.-Y. Lin, Y. Ran, X.-H. Xu and F.-L. Qing, Org. Lett., 2016, 18, 2419.

10 E. Nakamura and K. Sato, Nat. Mater., 2011, 10, 158.

11 (a) D. Ravelli, M. Fagnoni and A. Albini, Chem. Soc. Rev., 2013, 42, 97; (b) S. Fukuzumi and K. Ohkubo, Chem. Sci., 2013, 4, 561; (c) D. P. Hari and B. König, Chem. Commun., 2014, 50, 6688; (d) N. A. Romero and D. A. Nicewicz, Chem. Rev., 2016, 116, 10075.

12 I. Ghosh, T. Ghosh, J. I. Bardagi and B. König, Science, 2014, 346, 725.

13 (a) N. J. Treat, H. Sprafke, J. W. Kramer, P. G. Clark, B. E. Barton, J. R. de Alaniz, B. P. Fors and C. J. Hawker, J. Am. Chem. Soc., 2014, 136, 16096; (b) J. C. Theriot, C.-H. Lim, H. Yang, M. D. Ryan, C. B. Musgrave and G. M. Miyake, Science, 2016, 352, 1082.

14 (a) S. A. Ruetten and J. K. Thomas, J. Phys. Chem. B, 1998, 102, 598; (b) C. Koper, M. Sarobe and L. W. Jenneskens, Phys. Chem. Chem. Phys., 2004, 6, 319; (c) Molecular Fluorescence, ed. B. Valeur and M. N. Berberan-Santos, Wiley-VCH, Weinheim, 2012.

15 G. K. S. Prakash, C. Weber, S. Chacko and G. A. Olah, Org. Lett., 2007, 9, 1863.

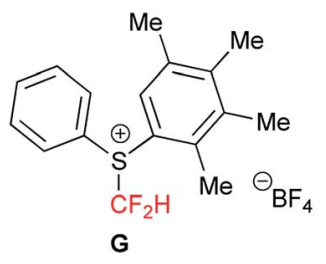

16 V. P. Mehta and M. F. Greaney, Org. Lett., 2013, 15, 5036. 17 CCDC 1533276 for 1 and CCDC 1533274 for 3c contain the supplementary crystallographic data, respectively $\dagger$

18 C. Ni, J. Liu, L. Zhang and J. Hu, Angew. Chem., Int. Ed., 2007, 46, 786. We conducted deprotection of the acetyl group in the amino-difluoromethylated product $3 \mathbf{e}$ to give the corresponding primary amine with the $\mathrm{CF}_{2} \mathrm{H}$ group (see the $\mathrm{ESI} \dagger$ ).

19 L. Flamigni, A. Barbieri, C. Sabatini, B. Ventura and F. Barigelletti, Top. Curr. Chem., 2007, 281, 143.

20 (a) G. M. Miyake and J. C. Theriot, Macromolecules, 2014, 47, 8255; (b) S. Okamoto, K. Kojiyama, H. Tsujioka and A. Sudo, Chem. Commun., 2016, 52, 11339.

21 For chlorotrifluoromethylation mediated by a $\mathrm{Ru}$ photocatalyst, see: S. H. Oh, Y. R. Malpani, N. Ha, Y.-S. Jung and S. B. Han, Org. Lett., 2014, 16, 1310.

22 J. J. Ritter and P. P. Minieri, J. Am. Chem. Soc., 1948, 70, 4045. 